\title{
Novos Aspectos da Genética e dos Mecanismos Moleculares da Morfogênese da Tiróide para o Entendimento da Disgenesia Tiroidiana
}

\begin{abstract}
RESUMO
A organogênese da tiróide ainda não está completamente elucidada, assim como também não se conhece o mecanismo patogenético da maioria dos casos de disgenesias tiroidianas. Vários genes têm sido identificados como importantes para a sobrevivência, a proliferação e a migração dos precursores das células tiroidianas e tem-se demonstrado que eles atuam de modo integrado. Além disso, por meio da geração de camundongos geneticamente modificados, diversos estudos têm trazido melhor entendimento para o papel destes genes na morfogênese tiroidiana. Finalmente, tem-se também evidenciado que mutações em alguns destes genes são responsáveis pelo desenvolvimento de disgenesias tiroidianas em crianças com hipotiroidismo congênito. O objetivo desta revisão é sumarizar os aspectos moleculares do desenvolvimento tiroidiano, descrever os modelos animais e respectivos fenótipos e oferecer novas informações sobre a ontogenia e a patogênese das disgenesias tiroidianas humanas. (Arq Bras Endocrinol Metab 2008; 52/9:1403-1415)
\end{abstract}

Descritores: Disgenesia tiroidiana; Hipotiroidismo congênito; Desenvolvimento da tiróide

\begin{abstract}
New Aspects of Genetics and Molecular Mechanisms on Thyroid Morphogenesis for the Understading of Thyroid Dysgenesia.

The elucidation of the molecular mechanisms underlying the very early steps of thyroid organogenesis and the etiology of most cases of thyroid dysgenesis are poorly understood. Many genes have been identified as important contributors to survival, proliferation and migration of thyroid cells precursors, acting as an integrated and complex regulatory network. Moreover, by generation of mouse mutants, the studies have provided better knowledge of the role of these genes in the thyroid morphogenesis. In addition, it is likely that a subset of patients has thyroid dysgenesis as a result of mutations in regulatory genes expressed during embryogenesis. This review summarizes molecular aspects of thyroid development, describes the animal models and phenotypes known to date and provides information about novel insights into the ontogeny and pathogenesis of human thyroid dysgenesis. (Arq Bras Endocrinol Metab 2008; 52/9:1403-1415)
\end{abstract}

Keywords: Thyroid dysgenesis; Congenital hypothyroidism; Thyroid development

\section{INTRODUÇÃO}

hipotiroidismo congênito (HC) é a endocrinopatia congênita mais comum, afetando cerca de 1:3.000 a 4.000 recém-nascidos (RN) (1). Um revisão

\author{
HELTON E. RAMOS \\ SuZANa NESI-França \\ RUI M. B. MACIEL
}

Laboratório de Endocrinologia Molecular, Disciplina de Endocrinologia, Departamento de Medicina, Escola Paulista de Medicina, Universidade Federal de São Paulo (HER, RMBM), São

Paulo, SP, Brasil; Disciplina de Endocrinologia, Departamento de Clínica Médica (HER), Unidade de Endocrinologia Pediátrica (SNF), Faculdade de Medicina, Universidade Federal do Paraná; Fundação Ecumênica de Proteção ao Excepcional (SNF); Curitiba, PR, Brasil.

Recebido em 15/1/2008 Aceito em 9/5/2008 
grupo heterogêneo de doenças relacionadas às alterações no desenvolvimento da tiróide, conjuntamente denominadas disgenesias tiroidianas (DT), responsabiliza-se por aproximadamente $85 \%$ de todos os casos de HC. Tradicionalmente, as DT são divididas em subgrupos: agenesia ou atireose, hemiagenesia, ectopia e hipoplasia; contudo, não parece satisfatória a classificação com base unicamente em aspectos morfológicos, uma vez que fenótipos semelhantes podem ser oriundos de eventos moleculares distintos. Nos últimos anos, a descoberta de genes (especialmente fatores de transcrição envolvidos na diferenciação das células foliculares tiroidianas) e outros mecanismos implicados na morfogênese tiroidiana possibilitaram maior esclarecimento sobre as bases genéticas da ontogênese tiroidiana. Entretanto, apenas 5\% dos pacientes com DT apresentam mutações nos genes candidatos: receptor do TSH (TSHR), PAX8, TITFI e FOXE1, indicando que sua patogênese é ainda muito mais complexa (1). Esta freqüência baixa de mutações nas populações estudadas pode ser explicada pelo fato de que as análises são, na sua maioria, limitadas às regiões codificadoras dos genes e, portanto, não excluiriam mutações potenciais existentes em outras regiões regulatórias, aspectos pós-zigóticos ou, mesmo, a existência de fenômenos epigenéticos como causa de DT (1). Adicionalmente, a ampla variabilidade fenotípica encontrada e a presença invariável de penetrância incompleta nos casos familiares apontam, ainda, para possíveis mecanismos multigênicos de herança não-mendeliana (2). Portanto, não obstante os avanços recentes na compreensão de muitas etapas do desenvolvimento tiroidiano, montante considerável de aspectos etiopatogênicos estão ainda bastante obscuros. Do ponto de vista clínico, um melhor entendimento dos mecanismos de controle morfogenéticos da tiróide seria extremamente relevante, uma vez que os distúrbios de desenvolvimento da glândula são responsáveis pela maioria dos casos de HC. Este artigo de revisão visa a sumarizar novos conhecimentos adquiridos a partir do estudo de modelos animais e de pacientes com DT, discutindo aspectos já estabelecidos e enfatizando os pontos ainda enigmáticos no entendimento do desenvolvimento normal da tiróide e de sua fisiopatologia molecular.

\section{GENÉTICA DO DESENVOLVIMENTO TIROIDIANO NORMAL}

A Tabela 1 resume os diversos passos do desenvolvimento tiroidiano normal, didaticamente divididos em especificação, formação do broto tiroidiano embrionário, migração do primórdio tiroidiano, lobulação e foli-

Tabela 1. Resumo das diferentes fases do desenvolvimento tiroidiano: aspectos embriológicos, morfológicos, genéticos e de produção de T4.

\begin{tabular}{|c|c|c|c|c|c|c|}
\hline \multirow{3}{*}{$\begin{array}{l}\text { Dia } \\
\text { embrionário } \\
\text { camundongo }\end{array}$} & \multirow{3}{*}{$\begin{array}{l}\text { Dia } \\
\text { embrionário } \\
\text { humano }\end{array}$} & \multirow[t]{3}{*}{ Morfologia } & \multicolumn{3}{|c|}{ Genes } & \multirow[t]{3}{*}{$\mathrm{T} 4$} \\
\hline & & & \multicolumn{2}{|c|}{ Reguladores } & Diferenciação & \\
\hline & & & $\begin{array}{l}\text { Titf1 Foxel } \\
\text { Pax8 Hhex }\end{array}$ & Ffgr2 & $\begin{array}{l}\text { Tg Nis } \\
\text { TPO Tshr }\end{array}$ & \\
\hline E8 & $20 d$ & Especificação & - & - & - & - \\
\hline E8.5 & $22 d$ & Primórdio tiroidiano & + & - & - & - \\
\hline E9.5 & $22-26 d$ & Broto tiroidiano & + & - & - & - \\
\hline E10.5 & $26 d$ & Migração & + & - & - & - \\
\hline E11.5 & $37 d$ & $\begin{array}{l}\text { Desaparecimento do duto } \\
\text { tiroglosso }\end{array}$ & + & + & - & - \\
\hline E12.5 & $44 \mathrm{~d}$ & $\begin{array}{l}\text { Expansão-fusão dos corpos } \\
\text { ultimobranquiais }\end{array}$ & + & + & - & - \\
\hline E13.5 & $48 d$ & $\begin{array}{l}\text { Final migração } \\
\text { Início foliculogênese }\end{array}$ & + & + & - & - \\
\hline $\begin{array}{l}\text { E14.5-15.5 } \\
\text { E15.5-16 }\end{array}$ & $50 d$ & $\begin{array}{l}\text { Lobulação e foliculogênese } \\
\text { Início da diferenciação }\end{array}$ & + & + & + & - \\
\hline E16.5 & $10-12 \mathrm{sem}$ & $\begin{array}{l}\text { Fim da diferenciação terminal } \\
\text { organogênese completa }\end{array}$ & + & + & + & + \\
\hline
\end{tabular}


culogênese, diferenciação funcional e hormonogênese e expansão da tiróide fetal.

\section{Especificação}

No embrião humano, a tiróide é o primeiro órgão endócrino a se desenvolver. Em sua forma madura compõem-se de dois grupos celulares distintos, com origens embrionárias diferentes, denominados células foliculares tiroidianas (CFT) e células parafoliculares (ou células C). Um espessamento do epitélio endodérmico, localizado no assoalho da linha média da faringe embrionária, correspondente à base da língua, abriga o conjunto de células que representa as CFT primordiais ou o primórdio tiroidiano. Esta estrutura primitiva pode ser observada por volta do E8-8.5 em camundongos e E20-22 em humanos. As CFT primordiais, a esta altura, já apresentam assinatura molecular específica - a coexpressão única de quatro fatores de transcrição: Hhex, Titfl, Pax8 e Foxel - que as diferencia de células do epitélio endodérmico vizinho (3). Este processo, em que as células primordiais recebem programação definida de mudanças morfológicas e moleculares a serem seguidas com a finalidade de se tornarem CFT chama-se especificação ou determinação (4). Não se conhece o mecanismo controlador, moléculas ou genes responsáveis pela indução deste processo; acredita-se na hipótese de possível sinalização oriunda do mesênquima adjacente ou do endotélio do saco aórtico primitivo (4). Portanto, problemas na etapa de especificação deveriam gerar agenesia tiroidiana (total ausência da glândula) como conseqüência do grave defeito de organogênese. Ao serem estudados, modelos animais com inativação específica de genes essenciais para a formação do intestino primitivo, como Nodal, fatores de transcrição reguladores do Nodal, FGF4, membros da família GATA ou Sox, e que, portanto, seriam potenciais candidatos a reguladores da especificação não foram completamente informativos. Na maioria destes modelos animais há interrupção do processo de desenvolvimento embrionário antes mesmo do surgimento do primórdio tiroidiano (5). Outros possíveis genes candidatos, mas ainda não identificados, seriam fatores de transcrição responsáveis pelo início da expressão e controladores dos genes Hhex, Titfl e Pax8 (5).

\section{Formação do broto tiroidiano embrionário}

Por volta do E9.5 em camundongos e E24 em humanos, o primórdio tiroidiano invagina-se e invade o mesênqui- ma adjacente, formando, no E10.5 em camundongos e no E26 em humanos, estrutura alongada, conhecida como broto tiroidiano primitivo. Este processo de crescimento e brotamento do primórdio tiroidiano envolve, evidentemente, aumento muito rápido do número de células progenitoras, porém, recentemente, demonstrou-se que isso não ocorre por proliferação celular, mas, possivelmente, por recrutamento de células do endoderma vizinho (4). Em seguida, o broto tiroidiano assume formato de divertículo e migra caudalmente em direção ao mesênquima. Nesta etapa, o divertículo tiroidiano ainda se comunica com o epitélio faríngeo por uma estrutura estreita, o duto tiroglosso, que se desfaz gradualmente e desaparece por volta do El1.5 no camundongo e do E37 em humanos, quando a tiróide primitiva perde definitivamente a comunicação com o assoalho faríngeo (3).

Problemas na rede de interação gênica durante a especificação e o brotamento tiroidiano podem significar prejuízo importante na sobrevivência e na proliferação das CFT primordiais. É justamente nesta fase que as CFTs caracterizam-se pela coexpressão singular de fatores de transcrição importantes para a morfogênese: Hhex, Pax8, Titfl e Foxel. Modelos animais transgênicos de inativação destes genes oferecem informações valiosas para o mecanismo de disgenesia. $\mathrm{Na}$ realidade, o estudo de animais mutantes para Hhex, Titfl e Pax8 permite observar que a morfogênese tiroidiana inicia-se, mas, em seguida, ocorre involução e subseqüente desaparecimento do broto tiroidiano primitivo.

\section{Migração do primórdio tiroidiano}

Por volta do E13-14 em camundongos e E44-48 em humanos, a tiróide primitiva alcança seu posicionamento final, anteriormente à traquéia e inferiormente à cartilagem cricóide, quando, por fim, funde-se com os corpos ultimobranquiais que contém as células derivadas da crista neural e precursoras das células C. Todo esse processo de migração dura, em humanos, quatro semanas e sua base genética já é parcialmente compreendida, com participação importante do fator de transcrição Foxel, reforçando a idéia de migração ativa, em vez de simples processo de movimentação passiva por remodelamento (6). Alguns outros eventos morfológicos das regiões cervical e oral podem ainda contribuir no direcionamento da tiróide primitiva para a sua localização final (7). A Figura 1 ilustra alguns aspectos da migração e da organogênese. 


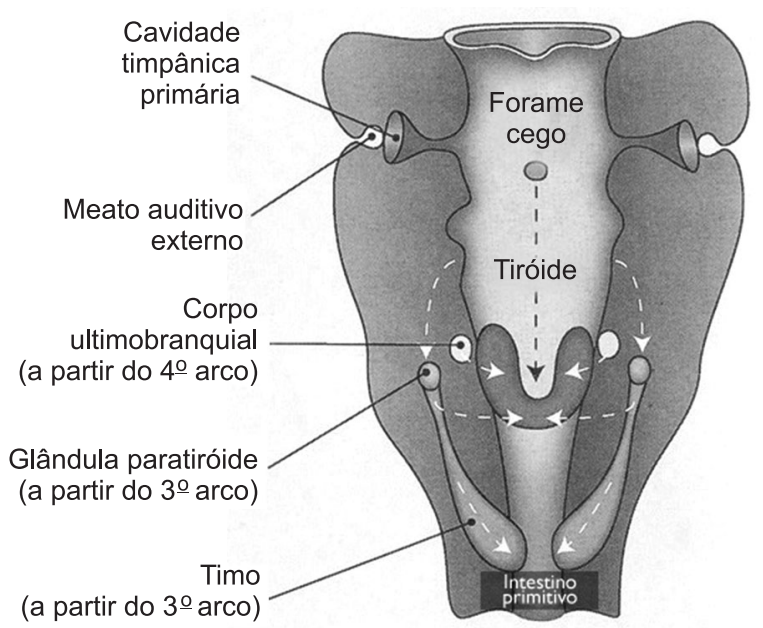

Figura 1. A tiróide forma-se a partir da migração do primórdio tiroidiano, que é derivado do assoalho do intestino primitivo. À medida que migra para baixo, associa-se às células derivadas do corpo ultimobranquial, provenientes do $4^{\circ}$ arco branquial, que contém as células C, para formar a glândula tiróide madura. $O$ forame cego é uma abertura formada pela invaginação do primórdio tiroidiano que se fecha posteriormente durante o desenvolvimento. As glândulas paratiróides e o timo derivam-se do $3^{\circ}$ arco branquial. A cavidade timpânica e o meato auditivo externo formam-se a partir do $1^{\circ}$ arco branquial (adaptado de Maciel, ref. 8).

\section{Lobulação e foliculogênese}

Nos E14-15 em camundongos e E60-70 em humanos, a tiróide primitiva tem formato semicircular e já possui dois lobos rudimentares paratraqueais. Em seguida, os lobos laterais crescem e a glândula assume seu formato final: dois lobos conectados por um estreito istmo. No E15.5 do camundongo e no E50 de humanos, inicia-se o processo de formação de folículos rudimentares - foliculogênese. Qualquer problema no processo chamado de lobulação pode comprometer a organogênese e a glândula, ao final, pode não formar os dois lobos simetricamente - hemiagenesia. Os mecanismos controladores da formação de lobos, da organogênese e da proliferação celular, nesta etapa, ainda são obscuros. Estudos recentes em modelos animais apontam a influência do gene Shh (sonic hedgehog) e de outras interações celulares envolvendo genes expressos em tecidos adjacentes $(9,10)$. Recentemente, modelo animal duplo-heterozigoto para a inativação de Titfl $\left(\mathrm{Titfl}^{+/-}\right) \mathrm{e}$ Pax8 $\left(\mathrm{Pax}^{+/-}\right)$, denominado DHTP (duplo-heterozigoto para Tifl e Pax8), mostrou elevada freqüência de hemiagenesia (2).

\section{Diferenciação funcional e hormonogênese}

$\mathrm{O}$ processo de diferenciação completa-se apenas quando a glândula atinge sua localização final; porém, esta localização normal não é exatamente requisito absoluto para que as CFTs completem sua diferenciação funcional plena; isso explica o fato de pacientes com glândula ectópica sublingual produzirem normalmente o hormônio tiroidiano (HT), porém, em menor quantidade (1). A diferenciação funcional inicia-se por volta de E14.5 e é conseqüência da expressão de proteínas essenciais para a produção do HT: tiroglobulina $(\mathrm{Tg})$, peroxidase tiroidiana (TPO), receptor do TSH (TSHR), "simportador" sódio/iodo, sodium/iodide symporter (NIS), DUOX (NADPH oxidases tiroidianas) e pendrina, que obedecem o padrão temporal preciso, o que indica que fatores genéticos possam ter influência. A expressão de genes específicos inicia-se em El4.5 com Tg, TPO e Tshr e, em seguida, em E16, com NIS. O início da produção de $\mathrm{T} 4$ já pode ser observado no E16.5 (1).

\section{Expansão da tiróide fetal}

Nesta etapa existe alta taxa de proliferação do tecido tiroidiano embrionário que proporciona grande aumento do seu tamanho e, ao mesmo tempo, a expressão de características próprias da arquitetura da glândula. No camundongo, o eixo hipotálamo-hipofisário exerce regulação completa do crescimento e função da tiróide somente após o nascimento. Já em seres humanos, a tiróide apresenta estrutura folicular organizada por volta de 10 a 11 semanas de gestação e aumenta de volume até o termo, porquanto o eixo hipotálamo-hipófise-tiroidiano já funciona durante a gestação. No animal adulto, a via AMPc induzida por TSH é o regulador principal do crescimento tiroidiano. Os modelos animais com inativação do Tshr ou seus ligantes apresentam invariavelmente a glândula hipoplásica na fase adulta. O modelo de animal transgênico que, na tiróide, superexpressa o receptor A2 de adenosina, e conseqüentemente, apresenta ativação constitutiva da adenilciclase, demonstra notável hiperplasia da tiróide na fase adulta (11). Contudo, no período embrionário E17, no contexto de ausência de Tshr funcional, o tamanho da glândula e o número de tirócitos permanecem inalterados e não se reduzem (12); adicionalmente, neste mesmo modelo transgênico, $\mathrm{O}$ volume tiroidiano não se altera no período embrionário e encontra-se normal até o nascimento (11). Em conclusão, no feto, o crescimento da glândula é controlado 
por mecanismos independentes da sinalização TSH-Tshr$\mathrm{AMPc}$, ainda não completamente esclarecidos. Interessantemente, o animal duplo-heterozigoto para inativação de Titfl e Pax8 apresenta defeito de organogênese da tiróide, com fenótipo de hipoplasia evidenciada em E15 e que persiste até o nascimento. Sendo assim, é possível que fatores de crescimento regulados por Titfl e Pax8 estejam envolvidos na proliferação de tirócitos imaturos na fase de crescimento da tiróide fetal (2).

\section{MODELOS ANIMAIS DE DISGENESIA TIROIDIANA}

\section{Titf1}

O Titfl (Nkx2-l ou T/EBP) é um fator de transcrição da família Nkx2 codificado por gene localizado no cromossomo 12 em camundongos e $14 \mathrm{ql} 3 \mathrm{em}$ humanos. Durante a vida embrionária, o Titfl expressa-se no primórdio tiroidiano, na traquéia, no pulmão, no cérebro e na neuro-hipófise (1). Animais com mutação inativadora do Titfl ( Titfl $^{-/-}$) apresentam fenótipo complexo, caracterizado por morte neonatal, agenesia tiroidiana, hipoplasia pulmonar, morfologia alterada da traquéia, alterações cerebrais e ausência da hipófise (13). O primórdio tiroidiano, identificado em fases mais precoces do desenvolvimento embrionário (E9), forma-se plenamente e é absolutamente normal. Contudo, em fases mais tardias, por volta do E10.5, a tiróide primitiva já apresenta significativa redução volumétrica e de expressão de Pax8, Foxel e Hhex. Subseqüentemente, o primórdio tiroidiano desaparece (E13), dando lugar somente a células apoptóticas. Compatível com o conhecido padrão de expressão de Titfl, ocorre desaparecimento não só das $\mathrm{CFT}$, mas também das células $\mathrm{C}$ e das células epiteliais do corpo ultimobranquial (14). Portanto, Titfl não é verdadeiramente necessário para a etapa de especificação, mas fundamental para a proliferação e sobrevivência dos dois tipos celulares; esta função é comprovadamente dose-dependente (fenômeno de haploinsuficiência), pois os animais $\mathrm{Titfl}^{+/-}$ apresentam incoordenação motora associada a leve hipertirotropinemia com níveis normais de T4 e fusão anormal dos corpos ultimobranquiais com a tiróide primitiva $(14,15)$. As vias genéticas controladas pelo Titfl não estão esclarecidas. Sabe-se que a ausência do Titfl determina, no embrião, a falta de expressão de genes como Bmp4 (bone morphogenetic protein 4) e Fgf8 ( $f$ broblast growth factor 8) nos pulmões e na hipófise, respectivamente (16). Portanto, paralelamente, o Titfl poderia controlar a sobrevivência das CFTs por meio de mecanismos semelhantes, envolvendo alguns fatores de crescimento. Consistente com esta hipótese é o fato de que o gene Fgfr2 tem sua expressão no primórdio tiroidiano por volta de Ell e animais knockout para este receptor apresentam agenesia tiroidiana (16). A proteína Titfl é definitivamente regulada de maneira tecido-específica, participando da regulação de diferentes genes em distintos tipos celulares. Na tiróide, além da importância embrionária, o Titfl desempenha claro papel na expressão de genes específicos da tiróide na fase adulta.

\section{Pax8}

O Pax8 (paired box gene 8) é membro de uma família de fatores de transcrição caracterizada pela presença do domínio paired domain (Prd), constituído de 128 aminoácidos que se liga a seqüências específicas do DNA. O Pax8, em células foliculares tiroidianas diferenciadas, reconhece e liga-se à região promotora de $\mathrm{Tg}$ e TPO e interage física e sinergisticamente com Titfl, sugerindo existência de cooperação, entre os fatores de transcrição, no controle da diferenciação tiroidiana. No embrião, expressa-se precocemente no primórdio tiroidiano (E8.5), no mielencéfalo e nos rins (4). Embriões de animais $\mathrm{Pax}^{\gamma^{-/}}$apresentam primórdio tiroidiano morfologicamente normal e comparável ao fenótipo selvagem nos estágios mais precoces, mas, em estágios mais tardios, por volta de E11.5, apresentam primórdio tiroidiano francamente hipoplásico e com expressão reduzida de outros fatores de transcrição, como Foxel e Hhex (5). Depois, ainda um dia mais tarde (E12.5), as CFT não são mais detectadas no primórdio primitivo. Animais $\mathrm{Pax}^{-/}$apresentam tiróide rudimentar composta quase exclusivamente por células C e morrem com duas a três semanas de idade por hipotiroidismo grave e retardo de crescimento e desenvolvimento generalizados (ossos, intestino, baço), porquanto a administração de T4 evita a morte destes animais (5). Similarmente ao Titfl, o Pax8 não é requisitado para a fase de especificação inicial, mas possui importância fundamental nas etapas seguintes do desenvolvimento e da sobrevivência celular. $\mathrm{O}$ animal heterozigoto $\mathrm{Pax}_{8^{+/}}$possui tiróide histológica e funcionalmente normal, diferindo, portanto, do fenótipo de DT encontrado em pacientes com mutações inativadoras em heterozigose (17). Recente estudo em modelo animal com dupla heterozigose para mutação no Pax8 e TitfI (modelo DHTP) revelou tiróide hipoplásica durante a vida fetal com alta incidência de hemia- 
genesia e redução na síntese de tiroglobulina; interessantemente, este modelo de DT é específico da linhagem de animais C57BL/6, não sendo observado em animais com a linhagem $129 / \mathrm{Sv}$, indicando possível atuação moduladora multigênica (2).

\section{Hhex}

O Hhex (hematopoietically expressed homeobox) é fator de transcrição primeiramente identificado em células hematopoiéticas multipotentes, localizado nos cromossomos 19 e 10q23.32 em camundongos e humanos, respectivamente. É expresso no coração, no cérebro, no primórdio tiroidiano e em outros órgãos derivados do intestino primitivo (fígado, timo, pâncreas, pul-

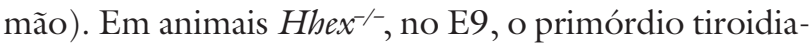
no existe e a expressão de Titfl, Pax8 e Foxel é normal. Mais tardiamente (E10), o brotamento tiroidiano é grandemente prejudicado e existe apenas pequeno número de células que não expressam Titfl, Pax8 e Foxel; em seguida, o primórdio tiroidiano desaparece ou apresenta-se gravemente hipoplásico. Portanto, parece que o Hhex, bem como os outros fatores de transcrição estudados, não são essenciais para a especificação, mas sim para a sobrevivência das células precursoras. Nos embriões de animais Titfl $^{-/-}$e $\mathrm{Pax}^{-/-}$, o Hhex é indetectável no remanescente tiroidiano, indicando a presença de uma rede de interação gênica entre estes fatores de transcrição $(1,18)$.

\section{Foxe 1}

O Foxel (TTF2, thyroid transcription factor 2) é codificado por gene situado no cromossomo $4 \mathrm{em}$ camundongos e 9q22 em humanos. Durante a vida embrionária expressa-se muito precocemente na tiróide, na bolsa de Rathke, na língua e no esôfago; mais tardiamente no palato, nas cóanas e no folículo piloso (19). A sua ausência nos animais Foxe $\mathrm{I}^{-/-}$não determina defeito na especificação, porém compromete gravemente a migração e a sobrevivência da tiróide primitiva: em El0 o primórdio tiroidiano ainda encontra-se atracado no assoalho faríngeo, e em estágios mais tardios existe apenas pequeno número remanescente de CFT capazes de sintetizar $\mathrm{Tg}$ (indicando capacidade preservada de diferenciação) ou simplesmente agenesia completa (6). Esta variabilidade fenotípica pode ser explicada por eventos epigenéticos ou influência do background genético individual. $\mathrm{O}$ animal $\mathrm{Foxe}^{-/-}$morre nas primeiras 48 horas de vida e apresenta fenótipo de agenesia tiroidiana e hipotiroidismo grave associado à fenda pa- latina (responsável pela morte neonatal). Em outro modelo animal, em que a expressão do Foxel restringiu-se às células do primórdio tiroidiano e não apareceu no endoderma faríngeo ( Titf $^{+/ \text {Foxel I }}$ ), ocorreu completa migração, o que sugere que este evento seja autônomo e dependente do controle intrínseco e local exercido por Foxel nas células precursoras da tiróide, não havendo interferência da ausência de Foxel no endoderma faríngeo vizinho $(5)$.

\section{Shh}

O Shh (sonic hedgehog) é codificado pelo gene localizado no cromossomo 5 em camundongos e $7 \mathrm{q} 36 \mathrm{em} \mathrm{hu}-$ manos. Não há expressão no primórdio tiroidiano, mas é amplamente detectado no epitélio do intestino primitivo, inclusive no assoalho faríngeo. Estudos com animais $S h h^{-/}$indicam sua grande importância na organogênese de várias estruturas, incluindo a tiróide. Neste modelo animal, as etapas precoces da morfogênese tiroidiana não sofrem alteração, mas parece haver prejuízo no processo de lobulação: no E15, a tiróide primitiva aparece apenas como massa tecidual localizada em região paratraqueal (9). Como o Shh ou seu receptor não são expressos em células tiroidianas, parece haver controle da lobulação por meio de mecanismos prejudicados na ausência de Shh. O desenvolvimento anormal de diversas estruturas vasculares próximas à tiróide que ocorre em animais $\mathrm{Shh}^{-/-}$seria mecanismo candidato. Esta hipótese é consistente com o relato de hemiagenesia em pacientes acometidos por doenças caracterizadas por defeitos vasculares e cardíacos congênitos, como a síndrome de Di George (20). Porém, a base genética do processo de lobulação ainda precisa ser amplamente explorada, possivelmente envolvendo fatores intrínsecos das CFT e do tecido adjacente (2).

\section{Nkx2.5}

O Nkx2.5 é um fator de transcrição essencial para a morfogênese cardíaca e que se expressa precoce e transitoriamente no primórdio tiroidiano (E8.5-9.5) (1). A inativação do gene $\mathrm{Nkx} 2.5 \mathrm{em}$ animais causa morte precoce (E9.5) no período fetal por defeitos graves na formação do coração e na especificação ventricular, o que dificulta a análise da importância deste gene na morfogênese tiroidiana (21). Embriões de animais $\mathrm{Nkx} 2.5^{-/}$apresentam primórdio tiroidiano hipoplásico se comparados ao tipo selvagem, mas não há alteração da expressão de outros fatores de transcrição (Pax8, Titfl e Foxel) (22). 


\section{Tshr}

O Tshr (thyroid-stimulating hormone receptor) é um membro da família dos receptores acoplados à proteína G. Este receptor é detectado em células tiroidianas por volta do E15, simultaneamente à produção de TSH pelos tirotrofos da hipófise fetal, e sua expressão aumenta consideravelmente a partir do E17. Os modelos animais disponíveis possibilitaram compreensão muito maior sobre a fisiologia do eixo hipotálamo-hipófisetiroidiano durante a vida embrionária. Tanto o Tshr $r^{\text {byt }} /$ Tshr hyt (com mutação puntiforme espontânea no $4^{\circ}$ domínio transmembrana do receptor) quanto o $T_{s} h r^{-1-}$ (com inativação do gene por recombinação homóloga em células-tronco) apresentam hipotiroidismo grave após o nascimento, associados à hipoplasia na vida adulta $(12,23)$. Na ausência de um Tshr funcionante existe importante diminuição da expressão de NIS e TPO na tiróide fetal; portanto, a sinalização via Tshr é de extrema importância no processo de diferenciação funcional. Entretanto, a síntese de DNA e o tamanho glandular, durante a vida fetal, não parecem ser influenciados pelo Tshr, sugerindo mecanismos de controle diversos do tamanho da tiróide no feto e no adulto (12).

\section{Tbx 1}

Animais $T b x I^{-/-}$exibem fenótipo de malformação vascular importante e, recentemente, é crescente a importância atribuída à influência dos grandes vasos per se ou de fatores reguladores e essenciais à vasculogênese na morfogênese tiroidiana. Acredita-se que a malformação vascular, direta ou indiretamente, possa contribuir ou causar defeito de migração ou de formação tiroidiana. $\mathrm{O}$ animal $T b x \mathrm{I}^{-/-}$possui atraso na migração do divertículo tiroidiano em direção ao saco aórtico e isso ocorre sem haver qualquer prejuízo na expressão do Foxel, único fator de transcrição de importância reconhecida no processo de migração. $\mathrm{O}$ resultado da inativação do gene Tbxl é um fenótipo de alteração vascular associado a defeito de bilobação e glândula de volume reduzido $(4,24)$.

\section{Outros genes}

Alguns genes da família Hox de fatores de transcrição poderiam estar envolvidos na morfogênese tiroidiana. A inativação do gene Hoxa 5 gera fenótipo de hipotiroidismo neonatal e menor expressão embrionária dos fatores Titfl, Pax8 e Foxel, associados a defeito na foliculogênese e na produção de $\operatorname{Tg}(25)$. Especialmente o gene Hoxa3, que é detectado no assoalho faríngeo e no primórdio tiroidiano, tem animal knockout que apresenta fenótipo de hipoplasia tiroidiana e de hipodesenvolvimento e migração anormal dos corpos ultimobranquiais, com conseqüente ausência do número de células $\mathrm{C}$ parafoliculares, associados à agenesia tímica $\mathrm{e}$ de paratiróide (26). O gene Eyal, apesar de presente nos corpos ultimobranquiais e não ser expresso no primórdio tiroidiano, gera fenótipo idêntico ao animal knockout para Hoxa3, indicando que o defeito na organogênese tiroidiana pode advir da ausência de fusão com os corpos ultimobranquiais durante a embriogênese (10). Um fenótipo idêntico é também observado em animais com mutação nos genes Pax3 e Endothelin-1, que são fundamentais para o desenvolvimento de estruturas derivadas da crista neural, fato que corrobora o conceito de interação importante e crítica entre os corpos ultimobranquiais e o divertículo tiroidiano $(27,29)$. $\mathrm{O}$ gene Fgfr2 (fibroblast growth factor receptor 2), detectado após formação do primórdio tiroidiano (E11.5) e seu ligante Fgfl0 (fibroblast growth factor 10) parecem representar vias significativas de diferenciação e proliferação da tiróide durante a vida embrionária, uma vez que os animais knockout apresentam fenótipo de agenesia $(16,29)$.

\section{GENÉTICA DA DISGENESIA TIROIDIANA HUMANA}

\section{TITF1}

Os rastreamentos de mutação do TITFI em populações de pacientes com DT apresentaram resultados negativos (30-32). Dada a importância fundamental deste gene nas morfogêneses pulmonar e cerebral, observada no modelo animal knockout, presume-se que a mutação inativadora em homozigose seria praticamente incompatível com a sobrevivência no período neonatal. De fato, os pacientes até então identificados, apresentam defeitos genéticos em heterozigose (deleção, inserção, mutação nonsense e missense) e quadro sindrômico que abrange problemas respiratórios no período neonatal (em alguns casos ausente ou com ampla variação de gravidade), distúrbios neurológicos (coreoatetose) e fenótipo tiroidiano variável entre eutiroidismo e $\mathrm{HC}$ (tiróide normal a hipoplásica) $(15,33-38)$. Na literatura, a análise de famílias estabelece forte relação com coréia hereditária benigna (distúrbio de movimento autossômico-dominante) (39). A imensa variação do fenótipo e a falta de correlação com a extensão do defeito genético indicam a presença de penetrância incompleta $\mathrm{e}$ 
influência de genes moduladores, assim como de fatores ambientais. Contudo, haploinsuficiência parece ser o mecanismo responsável pela presença de doença em indivíduos heterozigotos, assim como recentemente observado em estudo de animais Titfl $^{+/-}(15)$.

\section{PAX8}

O gene $P A X 8$, em humanos, localiza-se no cromossomo 2 e possui 12 éxons que codificam proteína de 450 aminoácidos. Dez mutações do gene PAX8 (oito missense, uma nonsense e uma deleção) já foram descritas em casos esporádicos e familiares com transmissão autossômica dominante de $\mathrm{HC}$ com DT, todas em heterozigose (Tabela 2) (40-48). O fenótipo tiroidiano é bastante variável (de casos leves àqueles com hipoplasia grave) entre indivíduos afetados da mesma família, o que indica penetrância incompleta $(41,45)$.

\section{FOXE1}

A síndrome de Bamforth-Lazarus caracteriza-se por fenda palatina, atresia bilateral de cóanas, epiglote bífida, alteração do couro cabeludo (cabelos espetados) e agenesia tiroidiana (49). O gene FOXEI é expresso continuamente na tiróide desde o período embrionário e possui um único éxon codificando uma proteína de 367 aminoácidos. Estudos recentes sugerem associação entre polimorfismos do gene e risco de DT (50). Entretanto, o rastreamento de mutação em indivíduos com DT e fenda palatina isolados ou em combinação não tiveram sucesso, sugerindo tratar-se de defeito genético raro (51). Três mutações do gene FOXEI em homozigose, todas localizadas no domínio forkhead de ligação ao DNA, já foram descritas em cinco pacientes com HC: S57N, A65V e R102C (52-54). Indivíduos heterozigotos são normais e os portadores de mutações com atividade funcional parcialmente preservada apresentam fenótipo incompleto, como ausência de atresia de cóanas e de epiglote bífida (53). A última mutação descrita (Rl02C), em homozigoze, foi encontrada em paciente com HC grave, ausência de concentração de iodo e tiroglobulina indetectável, mas associados à presença de tecido tiroidiano identificado por ultra-sonografia (52).

\section{NKX2.5}

O gene que codifica NKX2.5 em humanos localiza-se no cromossomo $5 \mathrm{q} 34$ e possui dois éxons codificando uma proteína de 324 aminoácidos. Estudos in vitro indicam que Nkx2.5 seja um forte indutor de NIS e interage sinergisticamente com Titfl; além disso, a expressão de isoforma com ação dominante negativa (N188K) em células tiroidianas provocou redução na transcrição

Tabela 2. Mutações descritas no gene PAX8 em hipotiroidismo congênito.

\begin{tabular}{|c|c|c|c|c|c|c|}
\hline $\mathrm{N}^{\circ}$ de casos & $\begin{array}{l}\text { Alteração } \\
\text { genética }\end{array}$ & Mutação & Proteína & $\begin{array}{l}\text { Morfologia } \\
\text { tiroidiana }\end{array}$ & $\begin{array}{l}\text { Estado } \\
\text { tiroidiano }\end{array}$ & Ref. \\
\hline 2 & Missense & $91 \mathrm{C}>\mathrm{T}$ & R31C & Hipoplasia & $\begin{array}{c}\mathrm{HC} \\
\text { Eutiroidiano }\end{array}$ & 44 \\
\hline 1 & Missense & $92 G>A$ & $\mathrm{R} 31 \mathrm{H}$ & Hipoplasia & $\mathrm{HC}$ & 45 \\
\hline 2 & Missense & $119 A>G$ & Q40P & $\begin{array}{l}\text { Hipoplasia } \\
\text { Normal }\end{array}$ & $\begin{array}{c}\mathrm{HC} \\
\text { Eutiroidiano }\end{array}$ & 41 \\
\hline 7 & Missense & $143 C>T$ & S48F & $\begin{array}{l}\text { Hipoplasia } \\
\text { Normal }\end{array}$ & $\begin{array}{c}\text { HC } \\
\text { Hipo subclínico }\end{array}$ & 43 \\
\hline 3 & Missense & $155 G>C$ & R52P & $\begin{array}{c}\text { Hipoplasia } \\
\text { Normal }\end{array}$ & $\begin{array}{c}\mathrm{HC} \\
\text { Eutiroidiano }\end{array}$ & 40,47 \\
\hline 3 & Missense & $161 A>G$ & S54G & Hipoplasia & $\mathrm{HC}$ & 46 \\
\hline 2 & Missense & $170 G>A$ & C57Y & Hipoplasia & $\mathrm{HC}$ & 48 \\
\hline 3 & Missense & $185 \mathrm{~T}>\mathrm{G}$ & L62R & $\begin{array}{l}\text { Hipoplasia } \\
\text { Cisto rudimentar }\end{array}$ & $\begin{array}{c}\text { HC } \\
\text { Hipo subclínico }\end{array}$ & 45 \\
\hline 3 & Deleção & $277 \mathrm{del}$ & $277 \mathrm{del}$ & $\begin{array}{l}\text { Hipoplasia } \\
\text { Normal }\end{array}$ & $\begin{array}{c}\text { HC } \\
\text { Hipo subclínico } \\
\text { Eutiroidiano }\end{array}$ & 42 \\
\hline 1 & Nonsense & $322 C>T$ & R108X & Hipoplasia & $\mathrm{HC}$ & 45 \\
\hline
\end{tabular}


de genes específicos, como pendrina e tiroglobulina $(55,56)$. Uma vez que este gene é fundamental para a morfogênese e a miogênese cardíaca, várias mutações inativadoras do gene NKX2.5 já foram identificadas em pacientes com cardiopatia congênita, visto que os defeitos de septo e distúrbios de condução figuram entre os fenótipos mais comumente encontrados (57-60). Durante a embriogênese, parece haver íntima relação entre o desenvolvimento tiroidiano e cardiovascular, sobretudo referente ao processo de migração do primórdio tiroidiano (4,61). Recentemente, três mutações heterozigóticas inativadoras (R25C, Al19S e R161P) foram descritas em quatro pacientes com DT (três com ectopia e um com agenesia). Os estudos funcionais in vitro demonstraram redução de transativação, capacidade de ligação ao DNA e efeito dominante negativo das proteínas mutantes (22). O grupo de estudo deste trabalho realizou o rastreamento de mutações do gene NKX2.5 em uma população de 157 pacientes com DT (17 com cardiopatia congênita) e foram identificadas quatro mutações novas (Dl6E, A80G, D105E e L245I) e uma previamente descrita (Al19S) em quatro indivíduos (todos com ectopia), também sem estigmas de cardiopatia congênita (22).

\section{TSHR}

O gene TSHR tem dez éxons, codifica proteína de 765 aminoácidos e localiza-se no cromossomo $14 \mathrm{q} 31$. A porção extracelular amino-terminal é codificada por nove éxons, enquanto os domínios transmembrana e citoplasmático são codificados por um único grande éxon. As mutações inativadoras do gene TSHR, em homozigose ou heterozigose composta, representam o achado genético mais comum em pacientes com DT. O espectro da manifestação fenotípica da hipossensibilidade ao TSH é grande, variando de hipertirotropinemia leve ou hipotiroidismo subclínico a grave HC com profunda hipoplasia da glândula (62). Parte desta variabilidade clínica pode ser explicada por atividade funcional residual das moléculas mutantes de Tshr, influência moduladora de outros genes e diferenças no background genético (1). Nos casos familiares, a doença tem herança autossômica recessiva e indivíduos heterozigotos possuem fenótipo normal ou níveis de TSH levemente aumentados (62). O rastreamento de mutações no Tshr em casos esporádicos ou familiares de hipotiroidismo não auto-imune mostrou que se trata de evento genético raro (63). Estudo recente de famílias com fenótipo de resistência ao TSH (RTSH), mas com padrão de herança autossômico dominante de alta penetrância, após adequada investigação dos locus candidatos, indica provável implicação de novos mecanismos moleculares ou epigenéticos (64-66).

\section{Outros genes}

$\mathrm{O}$ gene $\mathrm{SHH}$, classicamente relacionado à holoprosencefalia (ausência do lobo frontal do cérebro do embrião) e malformação de estruturas da linha média (dismorfismos craniofaciais, fenda palatina e alteração da morfogênese hipotálamo-hipofisária), possui diversas mutações descritas em casos isolados e familiares com herança autossômica dominante, com grande variabilidade fenotípica. A síndrome pode englobar diversos distúrbios endócrinos: diabetes insípido, hipoplasia adrenal, hipogonadismo e hipoplasia tiroidiana (67). O gene TBXI pode estar relacionado à síndrome $22 \mathrm{qll}$ (de Di George), que possui prevalência de $20 \%$ de hipotiroidismo em seus casos, às vezes, com manifestação tardia na vida adulta, sendo sugerida como causa aparente a deficiência do crescimento glandular (hipoplasia). O quadro clínico é complexo, envolvendo malformação vascular, dismorfismos faciais e agenesia de timo e paratiróide. A investigação não sistemática do fenótipo tiroidiano, nos pacientes já descritos com esta síndrome, encontrou alguns casos de hemiagenesia, hipoplasia lobar e agenesia de istmo em estudos de autópsia $(24,68)$.

\section{CONCLUSÃo}

Os estudos em animais geneticamente modificados $\mathrm{e}$ relatos de mutações humanas demonstram papel importante de alguns genes na embriogênese tiroidiana. Até o momento, quatro genes estão fortemente implicados: TITF1, PAX8, FOXE1 e TSHR. Os três primeiros, todos fatores de transcrição, muito conservados na escala zoológica (> 90\% de homologia entre camundongos e humanos), embora não específicos da tiróide, possuem coexpressão única no primórdio tiroidiano durante a embriogênese que se mantém na fase adulta. O fenótipo em humanos geralmente assemelha-se ao encontrado no modelo animal correspondente, porém as mutações já encontradas explicam apenas parte muito limitada dos casos de DT. Mesmo levando-se em conta que, na maioria das vezes, a análise é restrita à região codificadora do gene, é muito provável que outros genes não conhecidos estejam envolvidos. A exclusão dos já conhecidos genes candidatos, em uma série de casos 
familiares, reforça esta hipótese (69). Além disso, o modo de transmissão da doença pode ser diferente entre animais e humanos. Em animais, linhagens $\mathrm{Pax}^{+}{ }^{+}$ apresentam fenótipo aparentemente normal, enquanto linhagens $\mathrm{Titfl}^{+/-}$possuem hipotiroidismo subclínico e distúrbios motores. Por outro lado, em humanos, indivíduos com mutações heterozigóticas para os mesmos genes homólogos apresentam quadro clínico de DT com herança autossômica dominante. Em modelos animais, o gene Foxel está fortemente implicado em defeito de migração, enquanto em humanos, os casos de ectopia, que representam a maioria dos pacientes com DT, permanecem obscuros do ponto de vista genético, não sendo relacionados às poucas mutações descritas do FOXE1. Ainda existe controvérsia sobre o caráter passivo do processo de migração do primórdio tiroidiano e acredita-se que genes expressos no mesênquima vizinho deveriam ser também considerados candidatos na patogênese da ectopia (5). Analogicamente, na síndrome de Kallmann, em que existe distúrbio na migração de neurônios secretores do GnRH (gonadotropin-releasing hormone), o defeito genético advém de perda funcional de proteína extrínseca a estas células endócrinas (70). Ultimamente, importância crescente tem sido dada à influência dos vasos embrionários na organogênese tiroidiana, sugerindo que fatores vasculares devam ser adicionados à lista de genes candidatos $(4,61)$. Os dados recentes deste estudo apontam possível associação de ectopia com o gene NKX2.5, fator de transcrição conhecidamente importante para a diferenciação e morfogênese cardiovascular, porém os mecanismos moleculares implicados são desconhecidos, podendo incluir interação com outros fatores de transcrição extrínsecos da tiróide, como os pertencentes à família Tbx $(22,71,72)$.

A análise dos casos familiares descritos na literatura permite concluir que não existe padrão de transmissão claramente mendeliano, havendo alta incidência de alterações subclínicas da morfogênese tiroidiana em familiares dos pacientes com DT (69). A variabilidade fenotípica intrafamiliar é evidente nos casos de mutações no PAX8 e TITFl, indicando penetrância incompleta. Isso sugere modelo de doença de origem multigênica que, mais uma vez, recentemente, encontrou respaldo em modelo animal (DHTP). O número de genes candidatos é vasto e ainda largamente desconhecido. A Tabela 3 resume os diversos genes, sendo a maioria fatores de transcrição ou de crescimento, capazes de produzir defeitos de organogênese tiroidiana em modelos animais.
Tabela 3. Modelos animais de disgenesia tiroidiana.

\begin{tabular}{lll}
\hline Gene & Função & Fenótipo tiroidiano \\
Hhex & Fator de transcrição & Agenesia \\
\hline Titf1 & Fator de transcrição & Agenesia \\
\hline Pax8 & Fator de transcrição & Agenesia \\
\hline Pax3 & Fator de transcrição & Hipoplasia \\
\hline Foxe1 & Fator de transcrição & Agenesia ou ectopia \\
\hline Tshr & $\begin{array}{l}\text { Receptor acoplado } \\
\text { à proteína G }\end{array}$ & Hipoplasia \\
\hline Fgfr2 & $\begin{array}{l}\text { Receptor } \\
\text { tirosinoquinase }\end{array}$ & Agenesia \\
Fgf10 & Fator de crescimento & Agenesia \\
\hline Nkx2.5 & Fator de transcrição & Hipoplasia \\
\hline Hoxa3 & Fator de transcrição & Hipoplasia \\
\hline Hoxa5 & Fator de transcrição & $\begin{array}{l}\text { Defeito de diferenciação } \\
\text { funcional }\end{array}$ \\
\hline Tbx1 & Fator de transcrição & $\begin{array}{l}\text { Hipoplasia e } \\
\text { Hemiagenesia }\end{array}$ \\
\hline Shh & Morfogene & Hemiagenesia \\
\hline
\end{tabular}

Adaptado de De Felice e Di Lauro (ref. 1).

A identificação de novos genes, principalmente se forem relacionados ao processo de especificação ou em fases mais precoces da organogênese, seria extremamente útil (73). Ainda assim, a DT ocorre predominantemente como doença esporádica (95\% dos casos) e existe indubitável discordância na maioria dos casos documentados em gêmeos monozigóticos e forte preponderância no sexo feminino (principalmente para ectopia) $(74,75)$. Estes dados indicam que a DT, mesmo tendo causa genética, pode não ser hereditária e que mecanismos não-mendelianos, como eventos pós-zigóticos e fenômenos epigenéticos podem estar envolvidos na sua patogênese (76).

Agradecimentos: Este trabalho foi financiado pela Fundação de Amparo a Pesquisa do Estado de São Paulo (Fapesp), Auxílio à pesquisa no 06/54950-6 e Fundação Araucária (Programa de Pesquisa para o SUS, Protocolo $\mathrm{n}^{\circ}$ 9348). Os autores agradecem a colaboração dos Drs. Gisah Amaral de Carvalho e Luiz de Lacerda e valiosas discussões com os Drs. Peter Kopp, Samuel Refetoff e Massimo Tonacchera. Os autores declaram não haver conflitos de interesse científico neste artigo.

\section{REFERÊNCIAS}

1. De Felice M, Di Lauro R. Thyroid development and its disorders: genetics and molecular mechanisms. Endocr Rev. 2004; 25:722-46. 
2. Amendola E, De Luca P, Macchia PE, Terracciano D, Rosica A, Chiappetta $G$, et al. A mouse model demonstrates a multigenic origin of congenital hypothyroidism. Endocrinology. 2005;146:5038-47.

3. Trueba SS, Auge J, Mattei G, Etchevers H, Martinovic J, Czernichow $\mathrm{P}$, et al. PAX8, TITF1, and FOXE1 gene expression patterns during human development: new insights into human thyroid development and thyroid dysgenesis-associated malformations. J Clin Endocrinol Metab. 2005;90:455-62.

4. Fagman $\mathrm{H}$, Andersson $\mathrm{L}$, Nilsson $\mathrm{M}$. The developing mouse thyroid: embryonic vessel contacts and parenchymal growth pattern during specification, budding, migration, and lobulation. Dev Dyn. 2006;235:444-55.

5. Parlato R, Rosica A, Rodriguez-Mallon A, Affuso A, Postiglione $M P$, Arra $C$, et al. An integrated regulatory network controlling survival and migration in thyroid organogenesis. Dev Biol. 2004;276:464-75.

6. De Felice M, Ovitt C, Biffali E, Rodriguez-Mallon A, Arra C, Anastassiadis $\mathrm{K}$, et al. A mouse model for hereditary thyroid dysgenesis and cleft palate. Nat Genet. 1998;19:395-8.

7. Fagman $H$, Grande M, Edsbagge J, Semb H, Nilsson M. Expression of classical cadherins in thyroid development: maintenance of an epithelial phenotype throughout organogenesis. Endocrinology. 2003;144:3618-24.

8. Maciel RMB. Tireóide: fisiologia e avaliação diagnóstica. In: Saad MJA, Maciel RMB, Mendonça BB, editores. Endocrinologia. São Paulo: Atheneu; 2007. p. 299-330.

9. Fagman H, Grande M, Gritli-Linde A, Nilsson M. Genetic deletion of sonic hedgehog causes hemiagenesis and ectopic development of the thyroid in mouse. Am J Pathol. 2004;164: 1865-72.

10. Xu PX, Zheng W, Laclef C, Maire P, Maas RL, Peters $H$, et al. Eya1 is required for the morphogenesis of mammalian thymus, parathyroid and thyroid. Development. 2002;129:3033-44.

11. Ledent C, Dumont JE, Vassart G, Parmentier M. Thyroid expression of an $A 2$ adenosine receptor transgene induces thyroid hyperplasia and hyperthyroidism. Embo J. 1992;11:537-42.

12. Postiglione MP, Parlato R, Rodriguez-Mallon A, Rosica A, Mithbaokar $\mathrm{P}$, Maresca M, et al. Role of the thyroid-stimulating hormone receptor signaling in development and differentiation of the thyroid gland. Proc Natl Acad Sci USA. 2002;99: 15462-7.

13. Van Vliet G. Development of the thyroid gland: lessons from congenitally hypothyroid mice and men. Clin Genet. 2003;63: 445-55.

14. Kusakabe T, Hoshi N, Kimura S. Origin of the ultimobranchial body cyst: T/ebp/Nkx2.1 expression is required for development and fusion of the ultimobranchial body to the thyroid. Dev Dyn. 2006;235:1300-9.

15. Moeller LC, Kimura S, Kusakabe T, Liao XH, Van Sande J, Refetoff S. Hypothyroidism in thyroid transcription factor 1 haploinsufficiency is caused by reduced expression of the thyroid-stimulating hormone receptor. Mol Endocrinol. 2003; 17:2295-302.

16. Revest JM, Spencer-Dene B, Kerr K, De Moerlooze L, Rosewell I, Dickson C. Fibroblast growth factor receptor 2-IIlb acts upstream of Shh and Fgf4 and is required for limb bud maintenance but not for the induction of Fgf8, Fgf10, Msx1, or Bmp4. Dev Biol. 2001;231:47-62.

17. Mansouri A, Chowdhury K, Gruss P. Follicular cells of the thyroid gland require PAX8 gene function. Nat Genet. 1998;19: 87-90.
18. Martinez Barbera JP, Clements $M$, Thomas $P$, Rodriguez $T$, Meloy $D$, Kioussis D, et al. The homeobox gene Hex is required in definitive endodermal tissues for normal forebrain, liver and thyroid formation. Development. 2000;127:2433-45.

19. Dathan N, Parlato R, Rosica A, De Felice M, Di Lauro R. Distribution of the TITF2/FOXE1 gene product is consistent with an important role in the development of foregut endoderm, palate, and hair. Dev Dyn. 2002;224:450-6.

20. Scuccimarri R, Rodd C. Thyroid abnormalities as a feature of DiGeorge syndrome: a patient report and review of the literature. J Pediatr Endocrinol Metab. 1998;11:273-6.

21. Lyons I, Parsons LM, Hartley L, Li R, Andrews JE, Robb L, et al. Myogenic and morphogenetic defects in the heart tubes of murine embryos lacking the homeo box gene Nkx2-5. Genes Dev. 1995;9:1654-66.

22. Dentice M, Cordeddu V, Rosica A, Ferrara AM, Santarpia L, Salvatore $D$, et al. Missense mutation in the transcription factor NKX2-5: a novel molecular event in the pathogenesis of thyroid dysgenesis. J Clin Endocrinol Metab. 2006;91:1428-33.

23. Marians RC, Ng L, Blair HC, Unger P, Graves PN, Davies TF. Defining thyrotropin-dependent and -independent steps of thyroid hormone synthesis by using thyrotropin receptor-null mice. Proc Natl Acad Sci U S A. 2002;99:15776-81.

24. Fagman $\mathrm{H}$, Liao J, Westerlund J, Andersson L, Morrow BE, Nilsson $M$. The $22 q 11$ deletion syndrome candidate gene Tbx 1 determines thyroid size and positioning. Hum Mol Genet. 2007; 16:276-85.

25. Meunier D, Aubin J, Jeannotte L. Perturbed thyroid morphology and transient hypothyroidism symptoms in Hoxa5 mutant mice. Dev Dyn. 2003;227:367-78.

26. Manley NR, Capecchi MR. Hox group 3 paralogs regulate the development and migration of the thymus, thyroid, and parathyroid glands. Dev Biol. 1998;195:1-15.

27. Epstein JA. Pax3 and vertebrate development. Methods Mol Biol. 2000;137:459-70.

28. Kurihara $Y$, Kurihara $H$, Suzuki $H$, Kodama T, Maemura K, Nagai $\mathrm{R}$, et al. Elevated blood pressure and craniofacial abnormalities in mice deficient in endothelin-1. Nature. 1994;368: 703-10.

29. Celli G, LaRochelle WJ, Mackem S, Sharp R, Merlino G. Soluble dominant-negative receptor uncovers essential roles for fibroblast growth factors in multi-organ induction and patterning. Embo J. 1998;17:1642-55.

30. Hishinuma A, Kuribayashi T, Kanno Y, Onigata K, Nagashima $\mathrm{K}$, leiri T. Sequence analysis of thyroid transcription factor-1 gene reveals absence of mutations in patients with thyroid dysgenesis but presence of polymorphisms in the $5^{\prime}$ flanking region and intron. Endocr J. 1998;45:563-7.

31. Lapi $P$, Macchia PE, Chiovato L, Biffali E, Moschini L, Larizza D, et al. Mutations in the gene encoding thyroid transcription factor-1 (TTF-1) are not a frequent cause of congenital hypothyroidism $(\mathrm{CH})$ with thyroid dysgenesis. Thyroid. 1997;7:383-7.

32. Perna MG, Civitareale D, De Filippis V, Sacco M, Cisternino C, Tassi $V$. Absence of mutations in the gene encoding thyroid transcription factor-1 (TTF-1) in patients with thyroid dysgenesis. Thyroid. 1997;7:377-81.

33. Devriendt K, Vanhole C, Matthijs G, de Zegher F. Deletion of thyroid transcription factor-1 gene in an infant with neonatal thyroid dysfunction and respiratory failure. $\mathrm{N}$ Engl J Med. 1998;338:1317-8.

34. Iwatani N, Mabe H, Devriendt K, Kodama M, Miike T. Deletion of NKX2.1 gene encoding thyroid transcription factor-1 in two 
siblings with hypothyroidism and respiratory failure. J Pediatr. 2000;137:272-6.

35. Krude H, Schutz B, Biebermann H, von Moers A, Schnabel D, Neitzel H, et al. Choreoathetosis, hypothyroidism, and pulmonary alterations due to human NKX2-1 haploinsufficiency. J Clin Invest. 2002;109:475-80.

36. Pohlenz J, Dumitrescu A, Zundel D, Martine U, Schonberger W, Koo E, et al. Partial deficiency of thyroid transcription factor 1 produces predominantly neurological defects in humans and mice. J Clin Invest. 2002;109:469-73.

37. Willemsen MA, Breedveld GJ, Wouda S, Otten BJ, Yntema JL, Lammens $M$, et al. Brain-Thyroid-Lung syndrome: a patient with a severe multi-system disorder due to a de novo mutation in the thyroid transcription factor 1 gene. Eur $\mathrm{J}$ Pediatr. 2005;164:28-30.

38. Moya CM, Perez de Nanclares G, Castano L, Potau N, Bilbao JR, Carrascosa A, et al. Functional study of a novel single deletion in the TITF1/NKX2.1 homeobox gene that produces congenital hypothyroidism and benign chorea but not pulmonary distress. J Clin Endocrinol Metab. 2006;91:1832-41.

39. Breedveld GJ, van Dongen JW, Danesino C, Guala A, Percy AK, Dure LS, et al. Mutations in TITF-1 are associated with benign hereditary chorea. Hum Mol Genet. 2002;11:971-9.

40. Al Taji E, Biebermann H, Limanova Z, Hnikova O, Zikmund J, Dame $C$, et al. Screening for mutations in transcription factors in a Czech cohort of 170 patients with congenital and earlyonset hypothyroidism: identification of a novel PAX8 mutation in dominantly inherited early-onset non-autoimmune hypothyroidism. Eur J Endocrinol. 2007;156:521-9.

41. Congdon T, Nguyen LQ, Nogueira CR, Habiby RL, MedeirosNeto G, Kopp P. A novel mutation (Q40P) in PAX8 associated with congenital hypothyroidism and thyroid hypoplasia: evidence for phenotypic variability in mother and child. J Clin Endocrinol Metab. 2001;86:3962-7.

42. de Sanctis L, Corrias A, Romagnolo D, Di Palma T, Biava A, Borgarello G, et al. Familial PAX8 small deletion (c.989_992del ACCC) associated with extreme phenotype variability. J Clin Endocrinol Metab. 2004;89:5669-74.

43. Grasberger $H$, Ringkananont $U$, Lefrancois $P$, Abramowicz $M$, Vassart G, Refetoff S. Thyroid transcription factor 1 rescues PAX8/p300 synergism impaired by a natural PAX8 paired domain mutation with dominant negative activity. Mol Endocrinol. 2005;19:1779-91.

44. Komatsu M, Takahashi T, Takahashi I, Nakamura M, Takahashi I, Takada G. Thyroid dysgenesis caused by PAX8 mutation: the hypermutability with $\mathrm{CpG}$ dinucleotides at codon 31 . J Pediatr. 2001;139:597-9.

45. Macchia PE, Lapi P, Krude H, Pirro MT, Missero C, Chiovato L, et al. PAX8 mutations associated with congenital hypothyroidism caused by thyroid dysgenesis. Nat Genet. 1998;19:83-6.

46. Meeus L, Gilbert B, Rydlewski C, Parma J, Roussie AL, Abramowicz M, et al. Characterization of a novel loss of function mutation of PAX8 in a familial case of congenital hypothyroidism with in-place, normal-sized thyroid. J Clin Endocrinol Metab. 2004;89:4285-91.

47. Ramos HE, Boldarine VT, Nesi-França S, Chiamolera MI, Graf $H$, Carvalho GA, et al. Clinical and molecular analysis of thyroid hypoplasia: a population-based study. In: LATS Scientific Program and Abstract Book XII Congress Latin American Thryroid Society, Santiago, Chile; 2007. p. 35-6.

48. Vilain C, Rydlewski C, Duprez L, Heinrichs C, Abramowicz M, Malvaux $\mathrm{P}$, et al. Autosomal dominant transmission of conge- nital thyroid hypoplasia due to loss-of-function mutation of PAX8. J Clin Endocrinol Metab. 2001;86:234-8.

49. Bamforth JS, Hughes IA, Lazarus JH, Weaver CM, Harper PS. Congenital hypothyroidism, spiky hair, and cleft palate. J Med Genet. 1989;26:49-51.

50. Carre A, Castanet M, Sura-Trueba S, Szinnai G, Van Vliet G, Trochet $D$, et al. Polymorphic length of FOXE1 alanine stretch: evidence for genetic susceptibility to thyroid dysgenesis. Hum Genet. 2007;122(5):467-76.

51. Tonacchera M, Banco M, Lapi P, Di Cosmo C, Perri A, Montanelli L, Moschini L, Gatti G, Gandini D, Massei A, Agretti P, De Marco G, Vitti P, Chiovato L, Pinchera A 2004 Genetic analysis of TTF-2 gene in children with congenital hypothyroidism and cleft palate, congenital hypothyroidism, or isolated cleft palate. Thyroid 14:584-588

52. Baris I, Arisoy AE, Smith A, Agostini M, Mitchell CS, Park SM, et al. A novel missense mutation in human TTF-2 (FKHL15) gene associated with congenital hypothyroidism but not athyreosis. J Clin Endocrinol Metab. 2006;91:4183-7.

53. Castanet M, Park SM, Smith A, Bost M, Leger J, Lyonnet S, et al. A novel loss-of-function mutation in TTF-2 is associated with congenital hypothyroidism, thyroid agenesis and cleft palate. Hum Mol Genet. 11:2051-9.

54. Clifton-Bligh RJ, Wentworth JM, Heinz P, Crisp MS, John R, Lazarus JH, et al. Mutation of the gene encoding human TTF-2 associated with thyroid agenesis, cleft palate and choanal atresia. Nat Genet. 1998;19:399-401.

55. Dentice M, Luongo C, Elefante A, Ambrosio R, Salzano S, Zannini $M$, et al. Pendrin is a novel in vivo downstream target gene of the TTF-1/Nkx-2.1 homeodomain transcription factor in differentiated thyroid cells. Mol Cell Biol. 2005;25:10171-82.

56. Dentice M, Luongo C, Elefante A, Romino R, Ambrosio R, Vitale M, et al. Transcription factor Nkx-2.5 induces sodium/iodide symporter gene expression and participates in retinoic acidand lactation-induced transcription in mammary cells. Mol Cell Biol. 2004;24:7863-77.

57. Benson DW, Silberbach GM, Kavanaugh-McHugh A, Cottrill C, Zhang Y, Riggs $S$, et al. Mutations in the cardiac transcription factor NKX2.5 affect diverse cardiac developmental pathways. J Clin Invest. 1999;104:1567-73.

58. Hirayama-Yamada K, Kamisago M, Akimoto K, Aotsuka H, Nakamura $Y$, Tomita $H$, et al. Phenotypes with GATA4 or NKX2.5 mutations in familial atrial septal defect. Am J Med Genet A. 2005; 135:47-52.

59. McElhinney DB, Geiger E, Blinder J, Benson DW, Goldmuntz E. NKX2.5 mutations in patients with congenital heart disease. J Am Coll Cardiol. 2003;42:1650-5.

60. Schott JJ, Benson DW, Basson CT, Pease W, Silberbach GM, Moak JP, et al. Congenital heart disease caused by mutations in the transcription factor NKX2-5. Science. 1998;281:108-11.

61. Alt B, Elsalini OA, Schrumpf P, Haufs N, Lawson ND, Schwabe $\mathrm{GC}$, et al. Arteries define the position of the thyroid gland during its developmental relocalisation. Development. 2006;133: 3797-804.

62. Refetoff $\mathrm{S}$. The syndrome of resistance to thyroid stimulating hormone. J Chin Med Assoc. 2003;66:441-52.

63. Tonacchera M, Di Cosmo C, De Marco G, Agretti P, Banco M, Perri A, et al. Identification of TSH receptor mutations in three families with resistance to TSH. Clin Endocrinol (Oxf). 2007; 67:712-8.

64. Grasberger H, Mimouni-Bloch A, Vantyghem MC, van Vliet G, Abramowicz M, Metzger DL, et al. Autosomal dominant resis- 
tance to thyrotropin as a distinct entity in five multigenerational kindreds: clinical characterization and exclusion of candidate loci. J Clin Endocrinol Metab. 2005;90:4025-34.

65. Grasberger H, Vaxillaire M, Pannain S, Beck JC, Mimouni-Bloch $A$, Vatin $V$, et al. Identification of a locus for nongoitrous congenital hypothyroidism on chromosome 15q25.3-26.1. Hum Genet. 2005; 118:348-55.

66. Grasberger H, Van Sande J, Mahameed AH-D, TenenbaumRakover Y, Refetoff S. A familial thyrotropin receptor mutation provides in vivi evidence that the inositol phosphates/Ca2+ cascade mediates TSH action on thyroid hormone synthesis. J Clin Endocrinol Metab. 2007;92:2816-20.

67. Dubourg C, Bendavid C, Pasquier L, Henry C, Odent S, David V. Holoprosencephaly. Orphanet J Rare Dis. 2007;2:8.

68. Aggarwal VS, Liao J, Bondarev A, Schimmang T, Lewandoski $\mathrm{M}$, Locker $\mathrm{J}$, et al. Dissection of Tbx1 and Fgf interactions in mouse models of 22q11DS suggests functional redundancy. Hum Mol Genet. 2006;15:3219-28.

69. Castanet M, Lyonnet S, Bonaiti-Pellie C, Polak M, Czernichow P, Leger J. Familial forms of thyroid dysgenesis among infants with congenital hypothyroidism. N Engl J Med. 2000;343:441-2.

70. Legouis R, Hardelin JP, Levilliers J, Claverie JM, Compain S, Wunderle $\mathrm{V}$, et al. The candidate gene for the X-linked Kallmann syndrome encodes a protein related to adhesion molecules. Cell. 1991;67:423-35.

71. Habets PE, Moorman AF, Clout DE, van Roon MA, Lingbeek M, van Lohuizen $\mathrm{M}$, et al. Cooperative action of Tbx2 and Nkx2.5 inhibits ANF expression in the atrioventricular canal: implications for cardiac chamber formation. Genes Dev. 2002;16:1234-46.

72. Hiroi $Y$, Kudoh S, Monzen $K$, Ikeda $Y$, Yazaki $Y$, Nagai R, et al. Tbx5 associates with Nkx2-5 and synergistically promotes cardiomyocyte differentiation. Nat Genet. 2001;28:276-80.

73. Wendl T, Adzic D, Schoenebeck JJ, Scholpp S, Brand M, Yelon $D$, et al. Early developmental specification og the thyroid gland depends on han-espressing surrounding tissue and on FGF signals. Development. 2007;134:2871-9.

74. Devos H, Rodd C, Gagne N, Laframboise R, Van Vliet G. A search for the possible molecular mechanisms of thyroid dysgenesis: sex ratios and associated malformations. J Clin Endocrinol Metab. 1999;84:2502-6.

75. Perry R, Heinrichs C, Bourdoux P, Khoury K, Szots F, Dussault $\mathrm{JH}$, et al. Discordance of monozygotic twins for thyroid dysgenesis: implications for screening and for molecular pathophysiology. J Clin Endocrinol Metab. 2002;87:4072-7.

76. Vassart G, Dumont JE. Thyroid dysgenesis: multigenic or epigenetic ... or both? Endocrinology. 2005;146:5035-7.

Endereço para correspondência:

Rui M. B. Maciel

Laboratório de Endocrinologia Molecular, Unifesp

Rua Pedro de Toledo, 781, $12^{\circ}$ andar

04039-032 São Paulo SP

E-mail: rui.maciel@unifesp.br 